\title{
The Relationship between Teachers' Perceptions of Emotional Labor and Teacher Burnout and Teachers' Educational Level
}

\author{
By Racheli Zaretsky ${ }^{*} \&$ Yaacov J Katz ${ }^{\dagger}$
}

The purpose of this research was to examine the relationship between teachers' perceptions of emotional labor, teacher burnout and teachers' educational levels. The research sample consisted of 170 female Haredi (religiously ultra-orthodox and observant) teachers working in schools throughout Israel. The data were collected using the Emotional Labor of Teaching Scale (TELTS) and Teacher Burnout Questionnaire, and a demographic questionnaire formulated for the present study. The data collected in the study were processed using SPSS software. The two research hypotheses, namely a) teachers characterized by lower levels of burnout will use the natural acting technique associated with emotional labor whereas teachers typified by higher level of burnout will utilize the surface acting or deep acting emotional labor techniques; and b) teachers with higher levels of education will tend to use the natural acting technique associated with emotional labor in contrast to teachers with lower levels of education who will tend to utilize the surface acting or deep acting emotional labor techniques, were analyzed by ANOVA and MANOVA procedures. The main findings indicated that both teachers' burnout levels and teachers' levels of education differentially affected the use of the specific emotional labor techniques (surface, deep or natural acting). The conclusion of this study is that various variables can influence teachers' use of techniques associated with emotional labor. Changes in such variables, such as teachers' level of burnout and level of education, may improve management of emotions in teaching and improve their well-being.

Keywords: emotional labor, level of burnout, level of education.

\section{Introduction}

"Teaching Is Emotional Labor" (Larrivee, 2012, p. 37). "Emotions are dynamic parts of ourselves, and whether they are positive or negative, all organizations, including schools, are full of them" (Hargreaves, 1998, p, 835). Thus, emotional labor is perceived as a central and major factor associated with the wellbeing of members of the workforce in general and particularly those in the teaching profession as is evident in the above quotations. This paper will address the relationship between emotional labor of teachers and their levels of burnout as well as with their levels of education.

\footnotetext{
* PhD Student, School of Education, Bar-Ilan University, Israel.

${ }^{\dagger}$ Professor Emeritus, School of Education, Bar-Ilan University, Israel.
} 


\section{Emotional Labor}

\section{Feeling Rules}

According to the Meriam-Webster dictionary (2017), emotion is: "A conscious mental reaction (as anger or fear) subjectively experienced as a strong feeling usually directed toward a specific object and typically accompanied by physiological and behavioral changes in the body". The expression of feelings has many diverse social functions: it is related to gathering of information, influences social interactions and shapes interpersonal relationships with others (Wong et al., 2013). This relationship, between emotion and the social context, creates feeling rules (Hochschild, 1983; Hochschild, 2012) which can be described as norms that relate to the way a culture perceives the suitability or appropriateness of ways to express emotions in specific social interactions, including the degree and intensity of which expressions are expressed (Ekman \& Friesen, 1975; Matsumoto \& Hwang, 2013). Feeling rules differ from society to society and from culture to culture (Matsumoto \& Hwang, 2013). They change according to the specific context (Moran, Diefendorff, \& Greguras, 2013) and in accordance with the changes or transformations that take place (Brennan, 2006). Moreover, the reminders and the sanctions change from group to group and from situation to situation (Hochschild, 1983; 2012). Nevertheless, there are those who assert that even in the same given social context, and at the same point in time, feeling rules are dependent upon the expression of feelings or emotions, in terms of the subjective interpretation that everyone perceives in a specific situation (Ginat, 2011).

\section{Emotional Regulation}

Feeling rules require the individual, in many daily situations of his or her life, to try to hide certain emotions or feelings that are not congruent with his or her true or real feelings. This is done to minimize the discrepancy or gap that exists between the authentic feeling (What I am feeling) and the ideal feeling (What I am supposed to feel) as described by Hochschild (1983; 2012). This process of presentation or repression of emotion, via facial expressions, bodily gestures and or verbal expressions, which are fashioned to match the situation and the context, is termed "emotional regulation" in the research literature (see Hochschild, 1983; Gross, 1998; Grandey, 2000).

It is possible to identify two kinds of strategies for emotional regulation: a) an adaptive strategy, which includes re-examination or evaluation of the situation, problem solving or acceptance of the emotions, and b) a non-adaptive strategy, which is expressed through conscious repression of the emotion due to the desire to minimize negative tensions. It has been found that the use of adaptive strategies is related to lower levels of anxiety and depression, while the use of non-adaptive strategies care related to higher levels of these phenomena (Subic-Wrana et al., 2014). Different situations dictate the use of differential 
strategies for the regulation of emotion, since the rules for emotional expression change from context to context.

\section{Emotional Labor}

In the context of organizational and business employment, emotional regulation is defined as emotional labor. This concept was first introduced in 1983 by the sociologist, Arlie Hochschild (1983) in her groundbreaking volume, and was defined by her as emotional regulation that functions to the norms of the area of business/profession/vocation or of the organization. In this volume the consequences of emotional regulation in the work place in the service sector were examined vis-à-vis the organizational level as well as on the psychological level of the individual worker (Grandey, 2015).

\section{Techniques Associated with Emotional Labor}

Emotional labor is dependent upon active techniques for change or for the creation and matching of the feelings or emotions that are expressed in the context of paid work. Hochschild $(1983 ; 2012)$ identified two central techniques of emotional labor through which workers in fields that combine work with customers accept the rules that relate to the demonstration of emotions that are dictated to them by the organization employing them: (a) "surface acting" - the expression of an ideal emotion that is not in line with the authentic emotion and (b) "deep acting" - transformation of the ideal emotion into an authentic emotion with the goal of "toeing the line" concerning expression of emotions that is demanded by the organization. After a decade, a third technique was identified by Ashforth \& Humphrey (1993), "natural acting". This is the expression of genuine emotion. Here the individual spontaneously demonstrates authentic emotion which matches or suits the ideal emotion, without the need to perform any manipulation on the emotions.

\section{Emotional Labor in Teaching}

\section{Emotional Labor in Teaching: State of the research}

Teaching serves as one of the many professions that has been researched in the context of emotional labor. In fact, it is one of the most studied (Tsang, 2014). Over the years, many studies have examined a variety of aspects connected to emotional labor in teaching, including many recent studies (see Hagenauer \& Volet, 2014; Levine Brown et al., 2014; Ching-Sheue, 2015; Sahin, 2015) and meta-analyses (for example, Tsang, 2014; Ye \& Chen, 2015). This is in light of the strengthening, over the last few decades, of the perception that the profession of teaching belongs to the service sector, which perceives the system of relations between teachers and students as relations between 
service-providers and customers (Oplatka, 2011; Iltaf \& Gulzar, 2013) and views the teacher as a figure whose role is to create an emotional change in the attitudes of students toward studying, learning and education (Basim, Begenirbaş, \& Yalçin, 2013).

The study of emotional labor among teachers is found throughout the world and includes studies that were undertaken in many and different countries. Pfister (2015), who surveyed the academic literature that deals with emotional labor in the context of schools, found that these studies concentrated on countries in North America, Europe, Asia and Australia, while she did not find research that was undertaken in Africa or South America. She notes that only one study was undertaken in Israel in 2007 (see Pfister, 2015, pp. 32-35 for a table that presents the studies according to country).

The study of emotional labor among teachers and the research on its impact and consequences on their psychological and emotional welfare and well-being is one of the topics that has been well-researched in the field of emotional labor (Tsang, 2014). There are several reasons for this, which include: (1) emotional labor influences the efficiency and efficacy of the pedagogical-educational work of the teachers (Roberts, 2011; Sutton, 2004); (2) emotional labor influences the self-image of the teachers since, for them, the classroom becomes their main source of self-esteem, satisfaction and vulnerability (Roberts, 2011). Nevertheless, it has been found that the study of emotional labor in the teaching profession has a unique character, which differentiates it from the other service professions.

According to Larrivee (2012, p. 37) "teaching is emotional labor". To begin with, interaction with students is usually much longer, continuous and more powerful than interaction with clients in different service industries. Secondly, the frequency and degree of problematic behaviors (beginning with chatting during lessons and not paying attention through rude comments, verbal and physical violence and absences) to which teachers are exposed in schools are significantly higher than in other professions. This does not only disrupt the process of teaching, it also appears to be one of the central factors contributing to emotional exhaustion. This is because it is difficult to for teachers control feelings of frustration, anger and other negative emotional expressions when students continually to ignore their instructions or behave in ways that disrupt the class (Wróbel, 2013).

Hagenauer \& Volet (2014) point to two main reasons for the high interest in studying emotional labor in the field of teaching. (1) It was found that teachers experience a wide range of emotions, including positive emotions (such as pleasure, pride and satisfaction) and negative ones (such as anxiety, frustration, anger, sadness and embarrassment) and that these emotional experiences influence the well-being of the teachers, their satisfaction from the profession of teaching and the degree of danger or risk of them becoming burnt-out and leaving the profession. (2) It was found that the emotions of the teachers or the character of their emotional relationships with their students have an influence of the character of their teaching. As a result, they impact the quality of the product of teaching. 
However, as opposed to business organizations, the consequences of emotional labor in teaching are not limited to the organization or solely to the worker: there are far-reaching consequences for society, that impact different circles including the community, the country and even the world and, so it seems, the future generation as well. As a result, the study of emotional labor in the field of teaching in schools is not only theoretical. Its great importance is derived from the need to prevent negative influences on the educational system and on entire society (Sun, 2013). Moreover, the reality in Israel, like in other countries, positions the teachers as service providers, the students (and the parents) as clients or customers, and the school administration, the supervisor, the school board and the Ministry of Education as directors and employers (Oplatka, 2009; Ginat, 2011).

This phenomenon is even more conspicuous due to the policy of opening areas of registration of schools and the creation of inter-school competitions in cities. As a result, new feeling rules have been created that are expressly designed to keep students in school. According to these rules, it is expected that the teacher, among others, will avoid expressing emotions that are judged to be overly negative toward students, for fear that the latter will leave the school (Oplatka, 2011). As a result, we can summarize that the management of emotions is an inseparable part of role requirements in the teaching profession (Levine Brown, 2011).

\section{Emotional Labor Techniques used by Teachers}

As mentioned above, the emotional labor of teachers deals with the emotions that arise from their professional work with their students, their superiors, their head-teachers, their supervisors and Ministry of Education officials. The current research focuses on one front of the emotional labor of the teacher, that related to their relationship with their students. Results of research studies have indicated the existence of unique behaviors in the field of teaching, in the context of each one of the techniques of emotional labor. For example, Levine Brown (2011) has detailed the following behaviors in a comprehensive research study:

a. Surface acting: the teacher makes an effort to conceal from the students emotions that are considered to be undesirable: "In my work with students, I act differently from the way that I actually feel"; "Even when I am angry or worried, I cause people in my environment to think that my mood is good"; "In order to do my job, I pretend that I actually feel the emotions that people expect me to express/demonstrate".

b. Deep acting: the teacher makes an effort to authentically feel the emotions expected from himself or herself and to demonstrate them to the students: "I make an effort to really feel the emotions that I am expected to demonstrate at work"; "I really try to feel the emotions that they expect from me"; "I work hard in order to feel the emotions that are expected from me to demonstrate at work". 
c. Natural acting: the teacher manages her or his emotions in accordance with her or his authentic feelings, and this is what she or he demonstrates to her or his students in the most natural manner, without the need "to put on a show". "The emotions that I show my students match my real feelings"; "The emotions that I show my students come to me naturally".

\section{Burnout}

\section{Burnout: Definition and State of the Research}

Burnout is a term used in many fields in the social sciences and in administration sciences. Herbert Freudenberg (1974) during his work as a psychiatrist, examined the gradual process of "the emptying out of emotions" and the loss of motivation and obligation to the job, which is accompanied by a variety of psychological and physical symptoms which develop as a response to interpersonal stress factors at work. He defined burnout as a state of physical, emotional and psychological weariness or tiredness, with symptoms that include a decrease in the level of achievement, de-personalization and a decrease in the level of interest in work. Freudenberg represents the pioneers dealing with this concept, who began studying the phenomenon in the mid1970s in the United States. The main contribution made by Freudenberg and his counterparts was that of naming, describing and presenting the insight about this phenomenon, which turned out to be quite common. His conclusions were based on the results of various qualitative studies that included personal interviews of workers in different vocations in which they provided services to individuals who needed them. These studies focused on the phenomenon of burnout among the service providers (Maslach, Schaufeli, \& Leiter, 2001).

\section{Burnout in Teaching}

The teaching profession is thought of as being one of the professions most characterized by burnout. The research on this topic began in the early (Gavish \& Friedman, 2010) and has continued to this day. Research findings have shown that the main reason for burnout of teachers is related to personal characteristics of teachers. It appears that there are several personality characteristics that can increase the danger or risk of burnout. Among these characteristics, one finds the tendency for neuroticism, such as anxiety, lack of security or nervousness, the tendency toward passivity, introversion, worry about what others are thinking, obsessive thoughts about mistakes that were made in one's teaching, self-criticism and a low threshold for frustration (Larrivee, 2012). Another personal characteristic that was found to predict the risk of burnout among teachers is little experience in the field of teaching (Larrivee, 2012).

There are far-reaching consequences of burnout on teachers, from a decrease in the level of their job efficiency in the school to their leaving the profession. 
Nevertheless, these consequences do not end on the personal level of the teachers, because they also influence wider circles. It has been found, among other things, that teacher burnout has a significant impact on the students, beginning with the negative influence on their achievement and behavior through negative impacts of them dropping out from school (see, for example, Dworkin, 1987; LeCompte \& Dworkin, 1991). It has also been found that teacher burnout has a negative influence on the educational system on the national level, even to the point of posing a real threat to its stability (see, for example, Farber, 1991). Among the negative outcomes resulting in the high percentage of attrition from the teaching profession, we can identify a decrease in the quality of teachers and employment of inexperienced or unsuitable teachers, a phenomenon that creates instability in schools and impacts, in a dramatic way, the ability to plan and administer the educational system (Sperling, 2015).

\section{Burnout of Teachers and Emotional Labor in Teaching}

Results of numerous studies have shown the relationship between burnout and emotional labor in certain professions and vocations. For example, studies undertaken with nurses in hospitals (Celic et al, 2010) and with hotel hospitality workers (Shani, Uriely, Reichel, \& Ginsburg, 2014) indicated the existence of significant correlations between the two variables. However, no significant differences were found between emotional labor and burnout in other professions and vocations, such as in the field of care-giving, administration, office work and physical work (Brotheridge \& Grandey, 2002). In the field of teaching, on the other hand, only a few researchers have studied the relationship between emotional labor and burnout. Levine Brown (2011), who reviewed the literature that deals with this relationship among teachers, found that until the time of publication of her study, there had been very few quantitative studies on the topic (Brotheridge \& Grandey, 2002; Näring, Vlerick, \& van de Ven, 2012) and they all used extremely small samples (less than 40 research participants). In fact, she was the first researcher to examine this question with quantitative tools and with large samples.

Levine Brown (2011) asserts that due to the daily and dynamic interaction between teachers and their students, researchers found that teachers experienced an increase in their use of emotional labor. This increased use of emotional labor could conceivably create burnout, which includes symptoms of emotional exhaustion and exaggerated use of punishment in the classroom to achieve discipline (Näring, Canisius, \& Brouwers, 2011). Moreover, Levine Brown assumes that, based on the studies she reviewed, it would be logical to assert that it is possible that teacher burnout is derived from the fact that teachers are unaware that their emotional labor is an inherent part of their work. This assumption receives support from the conclusions of Diefendorff \& Gosserand (2003), who noted that by informing teachers about this phenomenon, and by training them in rules related to the demonstration of emotions and emotional labor, their levels of emotional labor and burnout can be moderated. 
Studies that examined the relationship between emotional labor and teacher burnout found that it is possible to delay or even prevent burnout by encouraging deep acting by teachers (Carson et al., 2011). In contrast, results of another study carried out among mental health professionals; indicate that the prevention of burnout is brought about by encouraging emotional labor characterized by natural acting (Grandey et al., 2012). In a study carried out in China among college teachers (Zhang \& Zhu, 2008), the researchers found that deep acting predicted burnout among; however, the burnout was less than when teachers used surface acting.

The present study aims to examine the relationship between emotional labor and teacher burnout specifically among Israeli female Haredi teachers.

\section{Teachers' Educational Level}

Results of research studies have indicated that the higher the teachers' level of education, the higher their sense of self-efficacy (Hoy \& Woolfolk, 1993; Cantrell, Young, \& Moore, 2003; Akbari \& Moradkhan, 2009). Moreover, in a study that examined teacher burnout in Israel, it was found that teachers who only possess a teaching diploma exhibited higher levels of burnout than teachers who held a master's degree (Zaretsky, 2016). In another study, Özan \& Şener (2014) examined, among other things, the relationship between the level of education of the teachers and their use of different techniques of emotional labor. These researchers found that teachers who have a master's degree tend to use the natural method of emotional labor as opposed to teachers who only hold a teaching diploma who use the other two techniques associated with emotional labor.

Alavinia \& Kurosh (2012) indicated that teachers who maintained higher levels of knowledge and proficiency were characterized by higher levels of teaching efficacy and lower levels of teacher burnout and stress. Swanson and Huff (2010) confirmed that teachers' command of their specific teaching subject and proficiency in their teaching were related to lower levels of teacher attrition and burnout. An increase in the level of academic education makes it possible for the teacher to not only advance economically, but also to achieve promotion to a variety of different positions.

\section{Rationale of the Study}

Based on the literature review presented above, which indicated the relevance of emotional labor to teaching and its relationship to other factors, specifically teacher burnout, the present study examined the expressions of emotional labor in teaching among female Israeli Haredi teachers, using a quantitative approach. As can be seen from the articles reviewed above, the topic has been widely studied in other countries: in the United States (see Levine Brown, 2011; Levine Brown et al., 2014), Western Europe (Holland - see Näring et al., 2006; 2011; 
2012), Eastern Europe (Poland - see Wróbel, 2013), Asia - Turkey (see Çukur, 2009; Özan \& Şener, 2014), Taiwan (see Ching-Sheue, 2015), Pakistan (see Itlaf \& Gulzar, 2013), and numerous others. In contrast, in the Israeli context, except for the studies undertaken by Ginat (2011) and Oplatka (2011), very few studies have researched the theory of emotional labor among teachers. One of the main innovations of the present study is that it uses a specially adapted instrument in the Hebrew language for the examination of emotional labor in teaching.

\section{Goal of the Study}

The present study aimed to identify the patterns of use of the three techniques of emotional labor (surface acting, deep acting and natural acting) among female Israeli Haredi teachers. In addition, the relationship between burnout level and level of education of the research participants and the emotional labor techniques used by them was examined.

\section{Research Hypotheses}

1. Teachers characterized by lower levels of burnout will use the natural acting technique associated with emotional labor whereas teachers typified by higher levels of burnout will utilizing surface acting or deep acting emotional labor techniques.

2. Teachers with higher levels of education will tend to use the natural acting technique associated with emotional labor in contrast to teachers with lower levels of education who will tend to utilize the surface acting or deep acting emotional labor techniques.

\section{Methodology}

\section{Participants}

The research sample included 170 Haredi (religiously ultra-orthodox) women who served as teachers in elementary and high school throughout Israel. The sample included women of whom (88.8\%) were born in Israel, $29 / 4 \%$ of them were in possession of a teaching diploma, $47 / 6 \%$ held bachelor's degrees and $23 \%$ held master's degrees. Fifty-seven percent of the teachers were employed in elementary schools and the rest in high schools. Mean age of the teachers was 32.03 years (SD 8.77) and the mean number of years of teaching seniority was 10.61 years (SD 8.28). The decision to investigate a homogenous sample, in terms of gender, was based on methodological considerations of neutralizing the possible influence of the gender variable on the research results. 


\section{Instruments}

In this study, we used three questionnaires:

1. A demographic questionnaire that was specially compiled for this study.

2. The Emotional Labor of Teaching Scale - TELTS (Levine Brown, 2011) which was translated into Hebrew. This questionnaire, which examined the level of emotional labor of the participants, includes 11 items on a Likert type scale ranging from 1 (low) to 5 (high). The scale reflects three sub-scales that examine the level of use of surface acting (reliability: $\alpha=.80$ ), deep acting (reliability: $\alpha=.58$ ), and natural acting (reliability: $\alpha=.65$ ). For each research participant, the score on each of the three scales was calculated and served as the mean score of participant's responses. A higher score reflected a higher level of use of emotional labor in teaching.

3. The Teacher Burnout Questionnaire (Friedman, 1999) examines the burnout of teachers and is based on Maslach, Jackson \& Leiter's (1996) original instrument. The questionnaire comprises 14 items on Likert type scale ranging from 1 (low) to 6 (high) and reflects one general factor (teacher burnout) with reliability of the entire questionnaire being $\alpha=.89$. The mean score for each participant on the burnout factor was based on all responses, with a higher score reflecting a higher level of burnout.

\section{Procedure}

Data collection was undertaken via internet-based responses to the research questionnaires. The link to the questionnaires was sent via e-mail to the teachers who participated in the study. In all, 170 full questionnaires were received.

\section{Results}

\section{Teacher Burnout and Emotional Labor}

To examine any possible differences between teachers characterized by low levels of burnout and teachers typified by high levels of burnout in relation to the use of emotional labor in teaching, we performed an ANOVA statistical procedure. Table 1 presents the means and the standard deviations of the participants' scores for this first hypothesis, namely: Teachers characterized by lower levels of burnout will use the natural acting technique associated with emotional labor whereas teachers typified by higher levels of burnout will utilizing surface acting or deep acting emotional labor techniques. 
Table 1. Means and Standard Deviations for Research Participants' Scores on Emotional Labor Factors and Levels of Burnout $(\mathrm{N}=170)$

\begin{tabular}{|l|c|c|c|c|}
\hline Factor & Level of burnout & N & Mean & SD \\
\hline \multirow{2}{*}{ Surface acting } & Low-level burnout & 92 & 2.85 & .78 \\
\cline { 2 - 5 } & High-level burnout & 78 & 3.29 & .70 \\
\hline \multirow{2}{*}{ Natural acting } & Low-level burnout & 92 & 3.96 & .58 \\
\cline { 2 - 5 } & High-level burnout & 78 & 3.69 & .55 \\
\hline \multirow{2}{*}{ Deep acting } & Low-level burnout & 92 & 3.31 & .83 \\
\cline { 2 - 5 } & High-level burnout & 78 & 3.38 & .64 \\
\hline
\end{tabular}

Results of the analysis indicated significant differences between teachers with a low level of burnout and teachers with a high burnout level, in relation to the technique of surface acting $\left[\mathrm{F}(1,168)=14.182, \mathrm{p}<.001, \eta^{2}=0.078\right]$. Teachers, who exhibited a high level of burnout, were found to be significantly higher in their use of the surface acting technique as opposed to teachers with a low level of burnout. Furthermore, significant differences were found between teachers with a low level of burnout and the teachers with a high level of burnout in relation to their use of natural acting $[\mathrm{F}(1,168)=9.245, \mathrm{p}<.01$, $\left.\eta^{2}=0.052\right]$. Teachers who exhibited a low level of burnout were found to make more use of this technique. We did not find significant differences between teachers with a low level of burnout and teachers with a high level of burnout regarding the use of deep acting $\left[F(1,168)=0.279, \underline{p}>.05, \underline{\eta}^{2}=0.002\right]$.

\section{Educational Level of the Teacher and Emotional Labor}

In order to examine second hypothesis, namely teachers with higher levels of education will tend to use the natural acting technique associated with emotional labor in contrast to teachers with lower levels of education who will tend to utilize the surface acting or deep acting emotional labor techniques, potential differences among teachers with different levels of education, and their use of emotional labor in teaching, were analysed by a one-way MANOVA procedure. Results showed that there was a significant difference according to level of education as presented in the following table.

Table 2. Means and Standard Deviations of the Participants' Scores on Emotional Labor Factors and Levels of Education $(\mathrm{N}=170)$

\begin{tabular}{|c|c|c|c|c|}
\hline Factor & Level of Education & N & Mean & SD \\
\hline Surface acting & Teaching Diploma & 50 & 3.32 & .76 \\
\cline { 2 - 5 } & Bachelor's Degree & 81 & 2.99 & .77 \\
\cline { 2 - 5 } & Master's Degree & 39 & 2.85 & .72 \\
\hline \multirow{3}{*}{ Natural acting } & Teaching Diploma & 50 & 3.71 & .54 \\
\cline { 2 - 5 } & Bachelor's Degree & 81 & 3.87 & .63 \\
\cline { 2 - 5 } & Master's Degree & 39 & 3.91 & .52 \\
\hline \multirow{3}{*}{ Deep acting } & Teaching Diploma & 50 & 3.45 & .71 \\
\cline { 2 - 5 } & Bachelor's Degree & 81 & 3.41 & .81 \\
\cline { 2 - 5 } & Master's Degree & 39 & 3.07 & .61 \\
\hline
\end{tabular}


Significant findings were found between levels of education and level of use of the surface acting technique $\left[F(2,167)=4.68, p<.05, \eta^{2}=0.053\right]$. To ascertain the source of the differences, we performed a post-hoc Scheffe test. The results indicated a significant difference between teachers who only held a teaching diploma and teachers with a master's degree in relation to their use of surface acting. Teachers in possession of a teaching diploma used surface acting significantly more than teachers with a master's degree. Furthermore, significant differences were found between teachers' levels of education and their levels of use of the emotional labor technique of deep acting $[F(2,167)$ $\left.=3.38, \mathrm{p}<.05, \eta^{2}=0.039\right]$. To examine the source of the differences, we conducted a post-hoc Scheffe test. Results indicated that there was a significant difference between teachers who held a master's degree and teachers who possessed a teaching diploma in the use of deep acting. Teachers with a teaching diploma were found to be significantly more prone to adopt the deep acting technique than teachers with a master's degree. In contrast to these results, no significant results were found between teachers' level of education and levels of use of the natural acting technique $[\mathrm{F}(2,167)=1.65, \mathrm{p}>.05$, $\left.\eta^{2}=0.019\right]$. However, a nonsignificant trend indicates that teachers with a master's degree, and to a lesser extent, teachers with a bachelor's degree, used the natural acting technique associated with emotional labor more than teachers who held a teaching diploma.

\section{Discussion}

This study examined the relationship between level of teacher burnout and level of teacher education on the one hand and the use of emotional labor techniques on the other. The first hypothesis was that there would be differences between teachers characterized by different levels of burnout and their use of the different techniques associated with emotional labor. The first hypothesis was confirmed, and significant differences were indicated between teachers with different levels of burnout and the use of surface acting. Teachers who had high burnout level were found to use the surface acting technique significantly more than teachers characterized by a low burnout level. These results support the findings of other studies that indicated a positive correlation between burnout symptoms and use of surface acting in general (Brotheridge \& Grandey, 2002; Cox, 2012). More specifically, these findings confirm the results of previous studies that indicated a positive relationship between a high level of burnout and the use of surface acting (Zhang \& Zhu, 2008; Yoga, Alaskan, \& Aru, 2012).

Results of the statistical analysis of the data also indicated that teachers with a low level of burnout tended to use natural acting significantly more than those with a high burnout level. This technique is unique since it is not actually acting, but rather an expression of authentic and naturally honest emotions and feelings. Therefore, some of the studies term this emotional labor technique as the use of genuine emotions, rather than natural acting (Yilmaz et al., 2015). Apparently, workers who express genuine emotions and feelings do not 
experience the emotional dissonance that workers experience when they feel compelled to use surface acting or deep acting to conform with conventional norms (see Holman, Chissick, \& Totterdell, 2002). This finding also confirms the research results indicated by Yilmaz et al. (2015) who found a negative correlation between burnout level and the expression of genuine emotions and feelings.

The second research hypothesis suggested that there would be differences between teachers with different educational levels and their use of emotional labor techniques in teaching. Statistical analysis of the results indicated that the use of surface acting was significantly more frequent among teachers who held teaching diplomas in comparison with teachers who held master's degrees. These findings support the conclusions of Özan \& Şener (2014) who examined the relationship between teachers' educational levels and the emotional labor techniques that they preferred. In addition, the findings of the present study indicate that teachers with a teaching diploma used deep acting significantly more than teachers with either a bachelor's or master's degree. These findings support the results of the study undertaken by Özan \& Şener (2014).

The results also indicated a non-significant tendency for teachers with higher educational levels (bachelor's and master's degrees) to use the natural acting technique more frequently than teachers with a teaching diploma, thereby confirming previous findings reported by Hoy \& Woolfolk (1993), Cantrell et al. (2003) and by Akbari \& Moradkhan (2009). This tendency of teachers with a higher educational level to use the natural acting technique confirms the findings of Yin (2016) who indicated that teachers who use natural acting to genuinely express their emotions in teaching are better able to competently fulfill their professional goals.

In conclusion it may be said that the results of the present study confirm the importance of emotional labor vis-à-vis the performance of teachers. Natural acting is significantly associated with less teacher burnout and stress, thereby enabling the teacher to get on with his or her job without a feeling of dissonance or frustration when facing students. In addition, the results clearly indicate a definite tendency of teachers with more advanced educational levels to use surface acting significantly less than teachers with lower levels of education.

\section{Limitations of the Research}

The sample was comprised solely of Haredi women teachers. Further research in Israel should address a more heterogeneous research sample that includes teachers of both genders as well as teachers from the other sectors in Israeli society.

\section{Recommendations for Future Research}

This study was a quantitative study. We recommend undertaking additional 
studies that adopt a mixed-methods approach. Combining quantitative with qualitative methods can enrich the knowledge that we gain, making it possible to examine the research issues more deeply and comprehensively and to expand the study's scope and possible conclusions.

The present study focused on a specific research population of teachers. This population did not include other types of education professionals, such as administrators, subject coordinators, educational counsellors, special education teachers etc. As seen from the literature review, the need to deal with emotional labor is found in diverse field of service provision. Thus, future research should include other members of the educational staff who fulfil roles other than that of direct teaching.

\section{Practical Recommendations for the Educational System}

The first practical recommendation relates to the assimilation among administrators, educational counsellors and teachers of the understanding that emotional labor is not something to be taken for granted, but rather a phenomenon that requires effort that can have a positive influence on the educationalist's feelings and resulting work efficiency.

Following Diekfendorff \& Grossrand (2003), and Levine Brown (2011), who indicated that knowledge, practice and assimilation of rules connected to the expression of emotion among teachers moderates the levels of emotional labor of the teachers and the levels of burnout, the importance in relating to the issues of emotional labor in education in different systems becomes clearer. It is vital to address these issues both in pre-service training and in in-service training of teachers in schools (Avdor, 2008). It is especially important to deal with the topic in in-service workshops for new teachers, etc. These recommendations stem from the need to minimize the level of teacher burnout as well as to increase teacher efficiency and effectiveness. This could impact not only teachers, as individuals, but also possibly contribute to the solving of problems on the school and system levels: Issues such as teacher attrition, high levels of turnover, lack of motivation, decrease in the level of efficiency, decrease in the level of commitment to the organization, and more, need to be more proactively addressed for the benefit of the educational system.

\section{Acknowledgement}

This paper is based on a post-graduate research study carried out at the School of Education, Bar-Ilan University. 


\section{References}

Akbari, R., \& Moradkhan, Sh. (2009). Iranian English teachers' self-efficacy: Do academic degrees and experience make a difference? Pazhuhesh-e Zabanha-ye Khareji, 56, 25-47. [Farsi].

Alavinia, P., \& Kurosh, S. (2012). On the would-be bonds between emotional intelligence and self-efficacy: The case of Iranian EFL university professors. Theory and Practice in Language Studies, 2(5), 956-964.

Ashforth, B. E., \& Humphrey, R. H. (1993). Emotional labor in service roles: The influence of identity. Academy of Management Review, 18(1), 88-115.

Avdor, S. (2008). Professional development of teachers and the place of academic training institutions as partners in these processes: A literature review and research findings from the world and Israel. Authority for the Training of Teaching Professionals in the Ministry of Education, Jerusalem. Retrieved from http://bit.ly/ 2sIKobY. [Hebrew].

Basim, H. N., Begenirbaş, M., \& Yalçin, R. C. (2013). Effects of teacher personalities on emotional exhaustion: Mediation role of emotional labor. Educational Science: Theory and Practice, 13(3), 1488-1496.

Brennan, K. (2006). The managed teacher: Emotional labor, education, and technology. Educational Insights, 10(2), 55-65.

Brotheridge, C. M., \& Grandey, A. A. (2002). Emotional labor and burnout: Comparing two perspectives of "People Work". Journal of Vocational Behavior, 60, 17-39.

Cantrell, P., Young, S., \& Moore, A. (2003). Factors Affecting Science Teaching Efficacy of Preservice Elementary Teachers. Journal of Science Education, 14(3), 177-192.

Carson, R. L., Plemmons, S., Tenplin, T. J., \& Weiss, H. M. (2011). You are who you are: A mixed-method study of affectivity and emotion regulation in curbing teacher burnout. In G. M. Reevy \& E. Feydenberg (Eds), Personality, Stress and Coping: Implications for Education, (pp. 239-265). Charlotte, NC: IAP Information Age.

Celic, M., Tabak, A., Uysal, M.P., Sigri, U., \& Turunc, O. (2010). The relationship between burnout and emotional labor of the employees in hospital sector. International Journal of Business and Management Studies, 2(1), 47-54.

Ching-Sheue, F. U. (2015). The effect of emotional labor on job involvement in preschool teachers: Verifying the mediating effect of psychological capital. Turkish Online Journal of Educational Technology, 14(3), 145.

Cox, M. E. (2012). Explorations into early care and education providers' job dissatisfaction and mental well-being: Expanding the reach of emotional labor. Dissertation Abstracts International Section A: Humanities and Social Sciences, 72(9-A), 3524.

Çukur, C. Ş. (2009). The development of the teacher Emotional Labor Scale (TELS): Validity and reliability. Educational Sciences: Theory \& Practice, 9(2), 559-574.

Diefendorff, J. M., \& Gosserand, R. H. (2003). Understanding the emotional labor process: A control theory perspective. Journal of Organizational Behavior, 24(8), 945-959.

Dworkin, A. G. (1987). Teacher Burnout in the Public Schools: Structural Causes and Consequences for Children. Albany, NY: SUNY Press.

Ekman, P. \& Friesen, W. V. (1975).Unmasking the face: A guide to recognizing emotions from facial expressions. Englewood Cliffs, NJ: Prentice Hall.

Farber, B. A. (1991). Crisis in Education: Stress and Burnout in the American Teacher. San Francisco, CA: Jossey-Bass. 
Freudenberg, H., J. (1974). Staff burnout. Journal of Social Issues, 30(1), 159-165.

Friedman, I. (1999). Teacher burnout: The concept and its measurement. Jerusalem: Henrietta Szold Institute.

Gavish, B., \& Friedman, I. (2010). Novice teacher's experience of teaching: A dynamic aspect of burnout. Social Psychology of Education, 13, 141-167.

Ginat, K. (2011). The researchers of manifest and latent emotions. Hed Chinuch, 86(1), 42-45. Retrieved from http://bit.ly/2FijgTN. [Hebrew].

Grandey, A.A. (2000). Emotional regulation in the workplace: A new way to conceptualize emotional labor. Journal of Occupational Health Psychology, 5(1), 95-110.

Grandey, A. A. (2015). Smiling for a wage: What emotional labor teaches us about emotion regulation. Psychological Inquiry, 26(1), 54-60.

Grandey, A. A., Foo, S. C., Groth, M., \& Goodwin, R. E. (2012). Free to be you and me: A climate of authentic alleviates burnout from emotional labor. Journal of Occupational Health Psychology, 17(1), 1-14.

Gross, J. J. (1998). The emerging field of emotion regulation: An integrative review. Review of General Psychology, 2(3), 271-293.

Hagenauer, G., \& Volet, S. (2014). 'I don't think I could, you know, just teach without any emotion': Exploring the nature and origin of university teachers' emotions. Research Papers in Education, 29(2), 240-262.

Hargreaves, A. (1998). The emotional politics of teaching and teacher development: With implications for educational leadership. International Journal of Leadership in Education: Theory and Practice, 1(4), 315-336.

Hochschild, A. R. (1983). The managed heart: Commercialization of human feeling. Berkeley, CA: University of California Press,.

Hochschild, A.R. (2012). The managed heart: Commercialization of human feeling (updated with a new preface). Berkeley and Los Angeles, CA: University of California Press.

Holman, D., Chissick, C., \& Totterdell, P. (2002). The effects of performance monitoring on emotional labor and well-being in call centers. Motivation and Emotion, 26(1), 5781.

Hoy, W.K., \& Woolfolk, A.E. (1993). Teachers' sense of efficacy and the organizational health of schools. The Elementary School Journal, 93(4), 355-372

Iltaf, H., \& Gulzar, A. (2013). Impact of expressivity and impulse strength on burnout and turnover intentions: Mediating role of deep acting. Journal of Business and Management, 7(4), 62-67.

Larrivee, B. (2012). Cultivation Teacher Renewal: Guarding against Stress and Burnout. Lanham, MD: Rowman \& Littlefield Education.

LeCompte, M.D., \& Dworkin, A.G. (1991). Giving Up on school: Student Dropouts and Teacher Burnouts. Newbury Park, CA: Corwin Press.

Levine Brown, E. (2011). Emotion matters: Exploring the emotional labor of teaching. Unpublished Doctoral dissertation, University of Pittsburgh, PA.

Levine Brown, E., Horner, C.G., Kerr, M.M.. \& Scanlon, C.L. (2014). United States teachers' emotional labor and professional identities. KEDI Journal of Educational Policy, 11(2), 205-225.

Merriam-Webster Online Dictionary. (2017). Emotion. Retrieved from http://bit.ly/ 2cLkSdf.

Maslach, C., Jackson, S. E., \& Leiter, M. P. (1996). Maslach Burnout Inventory manual (3rd ed.). Palo Alto, CA: Consulting Psychologists Press.

Maslach, C., Schaufeli, W.B., \& Leiter, M.P. (2001). Job burnout. Annual Review of Psychology, 52(1), 397-1, 397-422. 
Matsumoto, D., \& Hwang, H. C. (2013). Cultural similarities and differences in emblematic gestures. Journal of Nonverbal Behavior, 37, 1-27.

Moran, C. M., Diefendorff, J. M., \& Greguras, G. J. (2013). Understanding emotional display rules at work and outside of work: The effects of country and gender. Motivation and Emotion, 37(2), 323-334.

Näring, G.W.B., Canisius, A.R.M., \& Brouwers, A. (2011). Measuring emotional labor in the classroom: The darker emotions. In A. Caetano., S. Silva, \& M.J. Chambel (Eds), New challenges for a healthy workplace in human services, (pp. 127-139). Munich: Rainer Hampp Verlag.

Näring, G., Vlerick, P., \& van de Ven, B. (2012). Emotion work and emotional exhaustion in teachers: The job and individual perspective. Educational Studies, 38(1), 63-72.

Oplatka, Y. (2009). Emotion management and display in teaching some ethical and moral considerations in the era of marketization and commercialization. In P. A. Schutz \& M. Zembylas (Eds.), Advances in teacher emotion research: The impact on teachers' lives, (pp. 55-71). New York, NY: Springer.

Oplatka, Y. (2011). Service providers or educators? Hed Hachinuch, 86(1), 46-49. Retrieved from http://bit.ly/2HztrE0. [Hebrew].

Özan, M. B., \& Şener, G. (2014). Teaching and emotional labor. American International Journal of Social Science, 3(5), 111-119.

Pfister, L. L. (2015). Emotional display rules for clerical workers, teachers, custodians, and cafeteria workers in Pennsylvania $\mathrm{K}-12$ public school organizations. Unpublished doctoral dissertation, University of Pittsburgh, Pittsburgh, PA.

Roberts, K. R. L. (2011). Emotional labor, emotional expression, and emotional control in the K-12 classroom Unpublished doctoral dissertation, University of Alabama, Tuscaloosa, AL. Retrieved from http://bit.ly/2HxEMEM.

Sahin, E. (2015). Determination of associations between educational beliefs, emotional labor and self-efficacy in teacher candidates. Anthropologist, 19(2), 543- 555.

Shani, A., Uriely, N., Reichel, A., \& Ginsburg, L. (2014). Emotional labor in the hospitality industry: The influence of contextual factors. International Journal of Hospitality Management, 37, 150-158.

Sperling, D. (2015). Teacher attrition in the world: A review of information. Mofet, Tel-Aviv: Institute and the Inter-College Center for Information. [Hebrew].

Subic-Wrana, C., Manfred, E. B., Brähler, E., Stöber-Richter, Y., Knebel, A., Lane, R. D., \& Wilting, J. (2014). How is emotional awareness related to emotion regulation strategies and self-reported negative affect in the general population? Plos One, 9(3), 1-10.

Sun, Y. (2013). The developmental characteristics of preschool teachers' emotional labor and its relation to emotional exhaustion. Unpublished doctoral dissertation, Northeast Normal University, Changchun, China.

Sutton, R. E. (2004). Emotional regulation goals and strategies of teachers. School Psychology of Education, 7(4), 379-398.

Swanson, P., \& Huff, R. (2010). The relationship of Georgia's rural foreign language teachers' sense of efficacy to teacher attrition. The Rural Educator, 31(3), 16-29.

Tsang, K. K. (2014). A review of current sociological research on teachers' emotions: The way forward. British Journal of Education, Society \& Behavioural Science, 4(2), 241-256.

Wong, E., Tschan, F., Messerly, L., \& Semmer, N. K. (2013). Expressing and amplifying positive emotions facilitate goal attainments in workplace interactions. Frontiers in Psychology, 4, 188.

Wróbel, M. (2013). Can empathy lead to emotional exhaustion in teachers? The mediating 
Vol. 6, No. 2 Zaretsky \& Katz: The Relationship between Teachers' Perceptions...

role of emotional labor. International Journal of Occupational Medicine and Environmental Health, 26(4), 581-592.

Ye, M., \& Chen, Y. (2015). A literature review on teacher's emotional labor. Creative Education, 6, 2232-2240.

Yilmaz, K., Altinkurt, Y., Guner, M., \& Sen, B. (2015). The relationship between teachers' emotional labor and burnout level. Eurasian Journal of Educational Research, 59, 75-90.

Yozgat, U., Çalışkan, S. C., \& Ürü, F. O. (2012). Exploring emotional dissonance: On doing what you feel and feeling what you do. Procedia-Social and Behavioral Sciences, 58, 673-682.

Zaretsky, R. (2016). The theory of emotional labor in teaching: The impact of seniority of the teacher, age of the students and the level of burnout of teachers on their perceptions of the rules connected to demonstration of emotions, and on the use of techniques of emotional labor in teaching. Unpublished master's thesis, Bar Ilan University, Ramat-Gan, Israel. [Hebrew].

Zhang, Q., \& Zhu, W. (2008). Exploring emotion in teaching: Emotional labor, burnout, and satisfaction in Chinese higher education. Communication Education, 57(1), 105-122. 